\title{
SANITARY-HYGIENIC EVALUATION OF NOISE IN MANUAL ARC WELDING WITH COVERED ELECTRODES
}

\author{
O.G. LEVCHENKO ${ }^{1}$, V.A. KULESHOV ${ }^{1}$ and A.Yu. ARLAMOV ${ }^{2}$ \\ ${ }^{1}$ E.O. Paton Electric Welding Institute, NASU \\ 11 Bozhenko Str., 03680, Kiev, Ukraine. E-mail: office@paton.kiev.ua \\ ${ }^{2}$ NTUU «Kiev Polytechnic Institute» \\ 6/2 Dashavskaya Str., 03056, Kiev, Ukraine
}

\begin{abstract}
Presented are the results of measurements of noise characteristics at working place at the distance of $0.55 \mathrm{~m}$ from welding arc using covered electrodes designed for welding carbon and low-alloyed steels. It was established that the equivalent level of sound is $83-86 \mathrm{dBA}$, and the maximum level does not exceed 93 dBA. It is shown that in welding with covered electrodes the noise level is linearly increased with increase of welding current, here the noise at the working place is mainly contributed by welding process, and the noise from current generator and ventilation equipment is in the ranges of measurements error. The data are given, which can be used for sanitary-hygienic evaluation of noise level at the working place in definite processes of arc welding. 13 Ref., 7 Tables, 1 Figure.
\end{abstract}

$\boldsymbol{K} \boldsymbol{e} \boldsymbol{y} \boldsymbol{w} \boldsymbol{o} \boldsymbol{r} \boldsymbol{d} \boldsymbol{s}:$ electric arc welding, steel, electrodes MR-3, UONI-13/55, ANO-4, ANO-12, ANO-36, noise level, sanitary-hygienic evaluation

Welding and allied technologies remain the sources of many dangerous and harmful industrial factors, including an acoustic noise [1,2]. From the psycho-physiological and social-economical point of view the noise is any kind of sound, harmful for health, interfering the reception of useful signals and reducing the labor efficiency of a human [3]. In the structure of professional deceases this kind of «noise decease» as deafness together with deceases of breathing organs, locomotor apparatus and with vibration decease compose the main group of deceases of industrial workers [4].

Among the 80 welding technologies in accordance with ISO 857-1:1998 [5] the excessive noise exceeding the limiting allowable level (LAL) [6] is typical of many welding processes. Thus, among methods of fusion welding the gas, laser, plasma and electric arc welding, magneticpulsed, percussion, ultrasonic and explosion welding from methods of pressure welding, and resistance welding from combined welding are distinguished. However, in the national publications the quantitative data about acoustic noise in welding production, as a rule, are not given [1].

The aim of the present work was the investigation of noise environment at the working place during manual arc welding with covered electrodes (MR-3, UONI-13/55, ANO-4, ANO-12,
ANO-36), designed for welding carbon and lowalloyed steels.

Methods of investigation. The levels of noise were determined in the process of manual surfacing with $4 \mathrm{~mm}$ diameter electrodes, having different types of coatings (Table 1), on St.3 steel plate, arranged on welding table at the operating local exhaust ventilation of $1700 \mathrm{~m}^{3} / \mathrm{h}$ efficiency and $2 \mathrm{~kW}$ power. Welding rectifier VDU-506 was used as a power source. Distance from the place of arcing to the nearest wall was not less than $0.5 \mathrm{~m}$. The working place of a welder was at the distance of $0.55 \mathrm{~m}$ from welding arc.

The noise parameters were measured by integrating meter of noise level of the first class of accuracy (Bruel\&Kjaer noise meter of 2230 model), the functional and technical characteristics of which are in compliance with the requirements of the interstate standards (GOST 17187-2010) of CIS countries [7]. Noise meter has a verification certificate and allows determining the noise characteristics of up to $1 \mathrm{~dB}$ accuracy.

Table 1. Characteristics of electrodes applied for determination of level of noise in manual surfacing

\begin{tabular}{|c|c|c||}
\hline \hline Grade & Type of coating & $I_{\mathrm{w}}, \mathrm{A}$ \\
\hline MR-3 & Rutile & $140-220$ \\
\hline UONI-13 $/ 55$ & Basic & $130-160$ \\
\hline ANO-4 & Rutile & $140-210$ \\
\hline ANO-12 & Basic & $140-210$ \\
\hline ANO-36 & Rutile-cellulose & $130-180$ \\
\hline
\end{tabular}


Table 2. Level of background noise at the working place of welder at the distance of $0.55 \mathrm{~m}$ from the arc

\begin{tabular}{||c|c|c|c|c|c|c|c|c||}
\hline \multicolumn{8}{|c||}{ Parameters of noise, dBA } \\
\hline \multicolumn{7}{|c|}{$L_{\mathrm{eq}}$} & \multicolumn{3}{c|}{$L_{\text {op max }}$} & \multicolumn{3}{c|}{$L_{\text {op min }}$} \\
\hline \multicolumn{8}{|c|}{ Number of measurements } \\
\hline 1 & 2 & 3 & 1 & 2 & 3 & 1 & 2 & 3 \\
\hline 69.1 & 69.1 & 69.2 & 78.4 & 78.7 & 78.9 & 66.9 & 66.8 & 66.5 \\
\hline
\end{tabular}

The measurements and sanitary-hygienic evaluation of noise at the working place were carried out in accordance with the requirements of GOST 12.1.003-83, GOST 12.1.050-86 and DSN 3.3.6.037-99 [8-10]. Duration of measurement was equal to duration of electrodes burning (about $60 \mathrm{~s}$ ). Each measurement was three times repeated. As a component of technological noise the noise generated by the current generator and equipment of air ventilation was taken. Measurement of background noise, generated by auxiliary equipment, was made before the beginning of electric arc surfacing process. At all the measurements the noise levels with a frequency correction $A(\mathrm{dBA})$, required for finding the temporary nature of noise and carrying out of sanitary-hygienic evaluation, were recorded [6]: the equivalent level of sound $L_{\text {eq }}$, maximum $L_{\text {op max }}$ and minimum $L_{\mathrm{op} \mathrm{min}}$ levels of sound pressure.

Results of investigations. The measured levels of background and technological sound at the working place of operators are given in Tables 2 and 3. Surfacing with each type of electrode was made at current almost at the level of maximum allowable welding current (see Table 3 ).

Let us apply the obtained results for evaluation of noise in welding $L$. The recorded noise is composed of noise $L_{\mathrm{w}}$, generated by arc welding process, and background noise $L_{\mathrm{b}}$, generated by operation of auxiliary equipment. By using the principle of additivity of power flows in the point of measurement [11], the measuring level of noise can be determined as

$$
L=L_{\mathrm{w}}+10 \lg \left(1+10^{L_{\mathrm{b}}-L_{\mathrm{w}} / 10}\right) .
$$

If $L_{\mathrm{w}}-L_{\mathrm{b}} \geq 10$, then $L \approx L_{\mathrm{w}}$, as the addition is not more than $0.4 \mathrm{~dB}$ and commeasurable with the error of measurements. It follows from the analysis of obtained data (see Tables 2 and 3) that this condition is fulfilled for all the measurements. Consequently, the contribution of background noise can be neglected and the measuring noise as a welding one should be considered.

Let us determine the accuracy of obtained results [12]. The best estimate of measurements $N$ of the same value $L$ is equal to their average value:

$$
\bar{L}=\sum_{i=1}^{N} L_{i} / N .
$$

It can be expected that the true meaning of measuring value lies in the ranges of $\bar{L} \pm \delta \bar{L}$. The full error consists of instrumental or systematic error of noise meter $\delta L_{\text {instr }}= \pm 1 \mathrm{dBA}$ and random component of error $\delta \bar{L}_{\mathrm{r}}$ whose source, in the first turn, is the non-uniformity of the technological welding process. The random error is equal to the error of mean value:

$$
\delta \bar{L}_{\mathrm{r}}=\sigma_{L}=\frac{\sigma_{L}}{\sqrt{N}},
$$

where the standard or mean-square deviation of single measurement is equal to

$$
\sigma_{L}=\sqrt{\frac{1}{N-1} \sum_{i=1}^{N}\left(L_{i}-\bar{L}\right)^{2}} .
$$

Then the full error shall be

$$
\delta \bar{L}=\sqrt{\left(\delta L_{\text {instr }}\right)^{2}+\left(\delta \bar{L}_{\mathrm{r}}\right)^{2}} .
$$

By assuming that $L=L_{\text {eq }}$ and $L=L_{\text {op max }}$ we

\begin{tabular}{|c|c|c|c|c|c|c|c|c|c|c|}
\hline \multirow{4}{*}{$\begin{array}{l}\text { Grade of } \\
\text { electrode }\end{array}$} & \multirow{4}{*}{$I_{\mathrm{w}}, \mathrm{A}$} & \multicolumn{9}{|c|}{ Parameters of noise, dBA } \\
\hline & & \multicolumn{3}{|c|}{$L_{\mathrm{eq}}$} & \multicolumn{3}{|c|}{$L_{\mathrm{op} \max }$} & \multicolumn{3}{|c|}{$L_{\mathrm{op} \min }$} \\
\hline & & \multicolumn{9}{|c|}{ Number of measurements } \\
\hline & & 1 & 2 & 3 & 1 & 2 & 3 & 1 & 2 & 3 \\
\hline MR-3 & 200 & 83.1 & 83.4 & 82.7 & 89.6 & 90.1 & 89.9 & 68.3 & 68.4 & 67.9 \\
\hline UONI-13/55 & 150 & 82.4 & 82.8 & 82.4 & 90.5 & 90.3 & 91.9 & 68.7 & 69.3 & 69.0 \\
\hline ANO-4 & 200 & 86.0 & 85.9 & 86.1 & 89.3 & 90.0 & 90.4 & 70.2 & 69.8 & 70.1 \\
\hline ANO-12 & 200 & 84.6 & 84.2 & 84.7 & 92.8 & 92.7 & 93.0 & 69.5 & 69.5 & 69.4 \\
\hline ANO-36 & 170 & 83.5 & 83.4 & 83.2 & 92.1 & 89.9 & 91.9 & 68.0 & 67.9 & 68.1 \\
\hline
\end{tabular}
shall find the values of appropriate errors for the data given in Table 3 (Tables 4 and 5).

Table 3. Level of technological noise at the working place of welder at the distance of $0.55 \mathrm{~m}$ from the arc during surfacing using electrodes of different grades 
Table 4. Error in measurements of equivalent level of sound, dBA

\begin{tabular}{|c|c|c|c|c|c|c|c|c|}
\hline \multirow{3}{*}{ Grade of electrode } & \multicolumn{3}{|c|}{ Measured $L_{\mathrm{eq}}$} & \multirow{3}{*}{$\bar{L}$} & \multirow{3}{*}{$\delta L_{\text {instr }}$} & \multirow{3}{*}{$\delta \bar{L}_{\mathrm{r}}$} & \multirow{3}{*}{$\delta \bar{L}$} & \multirow{3}{*}{$\begin{array}{l}\text { Error of } L_{\mathrm{eq}} \\
\text { measurement }\end{array}$} \\
\hline & \multicolumn{3}{|c|}{ Number of measurements } & & & & & \\
\hline & 1 & 2 & 3 & & & & & \\
\hline MR-3 & 83.1 & 83.4 & 82.7 & 83.1 & 1 & 0.2 & 1 & $83 \pm 1$ \\
\hline UONI-13/55 & 82.4 & 82.8 & 82.4 & 82.5 & 1 & 0.1 & 1 & $83 \pm 1$ \\
\hline ANO-4 & 86.0 & 85.9 & 86.1 & 86.0 & 1 & 0.1 & 1 & $86 \pm 1$ \\
\hline ANO-12 & 84.6 & 84.2 & 84.7 & 84.5 & 1 & 0.2 & 1 & $85 \pm 1$ \\
\hline ANO-36 & 83.5 & 83.4 & 83.2 & 83.4 & 1 & 0.1 & 1 & $83 \pm 1$ \\
\hline
\end{tabular}

Table 5. Error in measurements of maximum level of sound, dBA

\begin{tabular}{|c|c|c|c|c|c|c|c|c|}
\hline \multirow{3}{*}{ Grade of electrode } & \multirow{2}{*}{\multicolumn{3}{|c|}{$\frac{L_{\text {op max }}}{\text { Number of measurements }}$}} & \multirow{3}{*}{$\bar{L}$} & \multirow{3}{*}{$\delta L_{\text {instr }}$} & \multirow{3}{*}{$\delta \bar{L}_{\mathrm{r}}$} & \multirow{3}{*}{$\delta \bar{L}$} & \multirow{3}{*}{$\begin{array}{c}\text { Error of } \\
L_{\text {op max }} \\
\text { measurement }\end{array}$} \\
\hline & & & & & & & & \\
\hline & 1 & 2 & 3 & & & & & \\
\hline MR-3 & 89.6 & 90.1 & 89.9 & 89.9 & 1 & 0.1 & 1.0 & $90 \pm 1$ \\
\hline UONI-13/55 & 90.5 & 90.3 & 91.9 & 90.9 & 1 & 0.5 & 1.1 & $91 \pm 1$ \\
\hline ANO-4 & 89.3 & 90.0 & 90.4 & 89.9 & 1 & 0.3 & 1.0 & $90 \pm 1$ \\
\hline ANO-12 & 92.8 & 92.7 & 93.0 & 92.8 & 1 & 0.1 & 1.0 & $93 \pm 1$ \\
\hline ANO-36 & 92.1 & 92.0 & 89.9 & 91.3 & 1 & 0.5 & 1.1 & $91 \pm 1$ \\
\hline
\end{tabular}

Table 6. Level of noise at the working place of welder at the distance of $0.55 \mathrm{~m}$ from the arc during surfacing using electrodes of different grades

\begin{tabular}{|c|c|c|c|c|c||}
\hline Grade of electrode & Type of coating & $I_{\mathrm{w}}, \mathrm{A}$ & $I_{\mathrm{s}}, \mathrm{A}$ & $L_{\mathrm{eq}}, \mathrm{dBA}$ & $83 \pm 1$ \\
\hline MR-3 & Rutile & $140-220$ & 200 & $90 \pm 1$ \\
\hline UONI-13 55 & Basic & $130-160$ & 150 & $81 \pm 1$ \\
\hline ANO-4 & Rutile & $140-210$ & 200 & $86 \pm 1$ & $85 \pm 1$ \\
\hline ANO-12 & Basic & $140-210$ & 200 & $90 \pm 1$ & $93 \pm 1$ \\
\hline ANO-36 & Rutile-cellulose & $130-180$ & 170 & $91 \pm 1$ \\
\hline
\end{tabular}

Table 7. Level of noise at the distance of $1 \mathrm{~m}$ from the arc in welding using electrodes MR-3 at different welding current

\begin{tabular}{|c|c|c|c|c|c|c|c|c|c|}
\hline \multirow{4}{*}{$I_{\mathrm{w}}, \mathrm{A}$} & \multicolumn{9}{|c|}{ Noise parameters, dBA } \\
\hline & \multicolumn{3}{|c|}{$L_{\mathrm{eq}}$} & \multicolumn{3}{|c|}{$L_{\text {op max }}$} & \multicolumn{3}{|c|}{$L_{\text {op min }}$} \\
\hline & \multicolumn{9}{|c|}{ Number of measurements } \\
\hline & 1 & 2 & 3 & 1 & 2 & 3 & 1 & 2 & 3 \\
\hline 150 & 79.8 & 80.3 & 80.2 & 85.9 & 88.9 & 84.9 & 73.6 & 76.4 & 72.1 \\
\hline 180 & 81.3 & 81.1 & 81.1 & 85.1 & 85.4 & 85.8 & 79.0 & 78.6 & 78.4 \\
\hline 210 & 82.7 & 82.4 & 82.4 & 86.0 & 85.9 & 85.6 & 80.3 & 80.3 & 80.1 \\
\hline \multicolumn{10}{|c|}{$L_{\mathrm{b}}, \mathrm{dBA}$} \\
\hline & 68.1 & 68.0 & 68.3 & 73.8 & 74.6 & 75.1 & 66.9 & 67.5 & 68.0 \\
\hline
\end{tabular}

It follows from Tables 4 and 5 that the measurements error is completely determined by value of instrumental error and, consequently, the further increase in number of measurements (more than 3) will not lead to decrease of full error. As the error is equal to $\pm 1 \mathrm{dBA}$, the noise level is presented at an accuracy of up to $1 \mathrm{dBA}$. The total results of analysis of all the obtained data are summarized in Table 6 .

Let us consider the nature of dependence of noise level on welding current within the ranges of its rated values for electrode MR-3, used in the widest range of welding current values (see Table 1). Results of noise measurements at the distance of $1 \mathrm{~m}$ from the arc are given in Table 7 .

Using the least squares method [12] the following linear relationship between the obtained data was found (Figure):

$$
L_{\mathrm{eq}}=0.04 I_{\mathrm{w}}+74.056 \text {. }
$$

The square of linear correlation value $R^{2}=$ $=0.9705$ indicates the high degree of validity of 


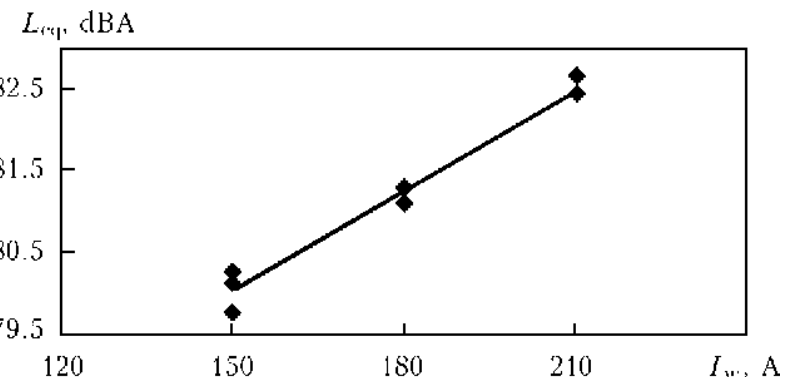

Dependence of noise level on welding current in surfacing with electrodes MR-3

the established linear dependence of noise level on welding current value. However, it is evident from the results of carried out investigations that quantitative increase in current strength has a negligible effect on noise level. Thus, the current increase by $40 \%$ led to growth of noise level only by $2.5 \%$. It is clear that the level of generated noise in surfacing with electrodes of other types and at other distances from the source of noise will also depend linearly on current value, as the physical principle of occurrence and spreading of acoustic noise in arc welding at different modes is one and the same, namely: the noise level is determined by the arcing stability.

Sanitary-hygienic evaluation of noise. In accordance with the requirements of GOST 12.1.003-83 [8] let us determine the temporary nature of noise and appropriate limits for the level of acoustic parameters being examined. As the change in sound level during all the measurements exceeds $5 \mathrm{dBA}$ (see Tables 2 and 3), the noise at electric arc welding should be classified as non-constant. For the non-constant noise the LAL are accepted for $L_{\mathrm{eq}}$ and $L_{\mathrm{op} \max }$. The LAL depends on kind of activity with account for difficulty and labor intensity. In the given work the manual arc welding is regarded as a physical work connected with accuracy, concentration or periodical aural control. For this kind of labor the safe $L_{\text {eq }}$ level for personnel during $8 \mathrm{~h}$ working day should not exceed $80 \mathrm{dBA}$, and the maximum sound level at the working place should not exceed $110 \mathrm{dBA}$. As it follows from the measured values (see Table 6), the latter condition is fulfilled, while the noise level exceeds the standard LAL. However, it is not right to state that the LAL was exceeded [13], as the comparison should be made at a single time base equal to $8 \mathrm{~h}$. However, we had a single measurement, continued only $1 \mathrm{~min}$. In practice, the processes of surfacing and welding are running with intervals. Moreover, the duration of noise episodes can be much lower than $8 \mathrm{~h}$, and the noise level here is much higher than $80 \mathrm{dBA}$. The standards admit operation under the conditions of increased (more than $80 \mathrm{dBA}$ noise level), but its duration should be, respectively, decreased according to the procedure regulated by GOST 12.1.050-86 [9].

\section{Conclusions}

1. It was found that electric arc process of welding with covered electrodes mainly contributes to the noise at working place and the contribution of noise generating by current generator and ventilation equipment is negligibly low and is in the ranges of measurements error.

2 . The level of generated noise is growing linearly with increase of welding current value, but change of level in the range of rated current values is negligible.

3. The equivalent level of sound is in the ranges of $83-86 \mathrm{dBA}$, and the maximum level does not exceed $93 \mathrm{dBA}$. The levels of recorded noise exceed officially the LAL ( $80 \mathrm{dBA}$ ) regulated by the standard documents for this kind of labor activity at $8 \mathrm{~h}$ working shift. However, for the correct sanitary-hygienic evaluation it is necessary to carry out comparison at a single time base.

4 . The given data can be used for sanitary-hygienic evaluation of noise episodes of definite processes of electric arc welding.

1. Levchenko, O.G. (2010) Labor protection in welding production: Manual. Kyiv: Osnova.

2. Encyclopedia of ILO. Welding and flame cutting. http://base.safework.ru/iloenc

3. Yudin, E.Ya., Borisov, L.A., Gorenshtejn, I.V. et al. (1985) Noise control in production: Refer. Book. Moscow: Mashinostroenie.

4. Kononova, I.G. (2010) Occupational disease of workers of machine-building enterprises. Ukr. Zhurnal Problem Med. Pratsi, 21(1), 9-14.

5. ISO 857-1:1998: Welding and allied processes - Vocabulary. Pt 1: Metal welding processes. Publ. 12.01 .98

6. Levchenko, O.G., Kuleshov, V.A. (2013) In-plant noise. Pt 1. Svarshchik, 2, 36-41.

7. GOST 17187-2010: Noise dosimeter. Pt 1: Specifications. Introd. 01.11.2012.

8. GOST 12.1.003-83: Safety general requirements. Introd. 01.07.84.

9. GOST 12.1.050-86: Methods of noise measurement on workplace. Introd. 01.01.87.

10. DSN 3.3.6.037-99: Sanitary codes of in-plant noise, ultrasound and infrasound. Introd. 01.12.99.

11. Grinchenko, V.T., Vovk, Sh.V., Matsipura, V.T. (2007) Principles of acoustics. Kiev: Naukova Dumka.

12. Taylor, J. (1985) Introduction to theory of errors. Moscow: Mir.

13. Levchenko, O.G., Kuleshov, V.A. (2013) In-plant noise. Pt 2. Svarshchik, 3, 44-48

Received 17.02.2014 